EPiC Series in Computing
Volume 60, 2019, Pages 170-180
Proceedings of 11th International Conference
on Bioinformatics and Computational Biology

\title{
Statistical Analysis of GLCM Texture Features and Microstructures in SEM Images of Crossostrea virginica Exposed to Atrazine
}

\author{
Abia Khan, Kavery Nivana Theethira Poonacha, Adrian Britt, Benjamin \\ McSweeney, Nicolette Santos, Grace Donovan, Valerie Yurk, Tara Scully \\ Department of Biology, George Washington University, Washington, D.C. \\ abiakhan22@gwu.edu, nkavery@gwu.edu
}

\begin{abstract}
The Eastern oyster, Crassostrea virginica, influences a range of economic and ecological systems. The effects of agricultural runoffs, such as the herbicide atrazine, on marine species, has not been well documented. To analyze the effect of atrazine, the oyster shell surface was analyzed. The shell protects the internal organs from predators. The shells of adult oysters are also required in the spawning of new oysters. This study analyzed the effects of atrazine on oyster shells using Scanning Electron Microscopy (SEM). SEM images were taken of juvenile oysters exposed to three different concentrations of atrazine $(30,10,3 \mu \mathrm{g} / \mathrm{L})$ to determine if there is a statistical significance in microstructure frequencies and GLCM texture features of three regions of the shell. Using a multivariate t-test, a significant difference was found in the texture features of the edge regions of the shells treated with $30 \mu \mathrm{g} / \mathrm{L}$ and $0 \mu \mathrm{g} / \mathrm{L}$ of atrazine. The same t-test found a significant difference in microstructures near the edge regions for shells treated with $10 \mu \mathrm{g} / \mathrm{L}$ and $0 \mu \mathrm{g} / \mathrm{L}$ of atrazine. These results provide computational strategies to distinguish shells treated with high concentrations of atrazine. Future work will tie evidence collected from imaging analysis into transcriptome data to illustrate the genetic impacts of atrazine exposure.
\end{abstract}

\section{Introduction}

The Eastern oyster, Crassostrea virginica, gains its popularity not only because of its well known commercial use but also because it provides habitats for other organisms and filters water in the ecosystem. Due to this integral role, the key determinants owing to their decline in populations have recently become a topic of interest in research. One such determinant is herbicides. Glyphosate, the compound found in roundup, the most commonly used herbicide, was recently determined to be a cancer-causing agent. Atrazine right behind glyphosate is the second most commonly used herbicide 
in the United States. However, unlike glyphosate, atrazine has been banned in Germany and Italy since 1991 and most of Europe since 2004 [1] (journal). At the molecular level in humans, atrazine has been found to spontaneously bind to Human Serum Albumin (HSA) changing its conformation and secondary structure [11] (journal). HSA is an important carrier of transport proteins and is one of the most abundant proteins in the blood plasma. Therefore, a structural change in HSA, can have serious harmful effects on the human body. In relation to marine ecosystem, atrazine has been found to affect both the flora and fauna. The most significant research proving the harmful effects of atrazine were done on frogs that changed into hermaphrodites after exposure to atrazine [6] (journal). In the pacific oyster (Crassostrea gigas), the creation of aneuploidy during development has been linked to increased exposure to atrazine [2] (journal). However, little research has been done on the effect of atrazine on the Eastern Oyster. The shell of the oyster is integral to its survival. This hard outer layer protects the internal organs to allow for their proper functioning. Apart from aiding the survival of the oyster itself, the shells of adult oysters are also required in spawning of new oysters. Therefore, the shell is integral to the continued survival of the species. Due to this important role of the oyster shell, this study uses scanning electron microscopy to assess the effect that atrazine has on the growth and maintenance of the shell in the Eastern Oyster.

In this paper, we use two different methods to analyze the effect of atrazine on the shell. The first method uses Gray Level Co-Occurrence Matrix (GLCM) texture methods. The GLCM texture method is a way of extracting second order statistical texture features from gray-level images (in this case images obtained from a Scanning Electron Microscope (SEM)). The statistical measures from this matrix are extracted from how often pairs of pixels with a specified value occur together in a spatial area. Textural features are perceived patterns, variations, and randomness across image pixels [5] (journal). Imaging devices, such as computer-aided diagnostics rely on quantitative measurements of textures as input that aim to characterize biological or disease status [4] (journal). It is unclear if these features behave similarly to unconventional imaging biomarkers such as tumor volume etc. This paper investigates texture features as potential imaging biomarkers for discriminating shells exposed to atrazine at varying levels of concentration. The proposed method is accomplished in three stages: obtaining the image, computational feature extraction, and classification. Statistical analysis is used to obtain the best features for classification, which is to differentiate between the shells exposed to different treatment groups.

The second method uses the frequency of the various microstructures that occur during shell growth to analyze the effects of atrazine on the shell. Crassostrea virginica shell structures have typical biological composite structures with various distributions and organizations of complex carbonate layers, commonly referred to as microstructures. The crystal microstructures that mollusks have employed in shell formation of Crassostrea virginica are complex. SEM microstructural analysis shows the occurrence of such microstructures. Through SEM and other microscopy methods, the following microstructures have been standardized [9] (book). 
Statistical Analysis of GLCM Texture Features and Microstructures in SEM Images ... A. Khan et al.

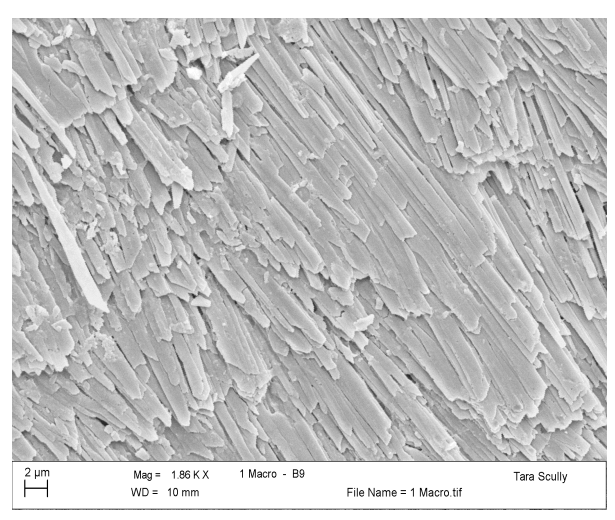

Figure 1a. The nacreous layer found on the inner surface of the mantle is composed of randomly assorted mineralized granules that grow laterally. These granules form flattened crystals, which are covered by an organic membrane.

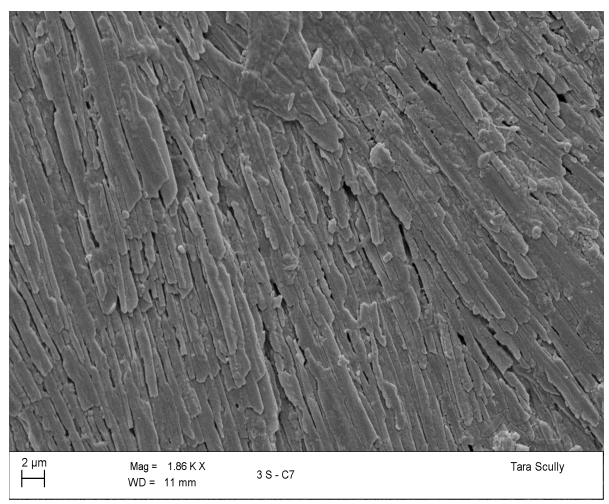

Figure 1b. The foliated microstructure derived from calcitic prisms, particularly from those with internal foliated structure. A smaller number of taxa acquired the ability to secrete calcite in their shells as prismatic and foliated microstructures. 
Statistical Analysis of GLCM Texture Features and Microstructures in SEM Images ... A. Khan et al.

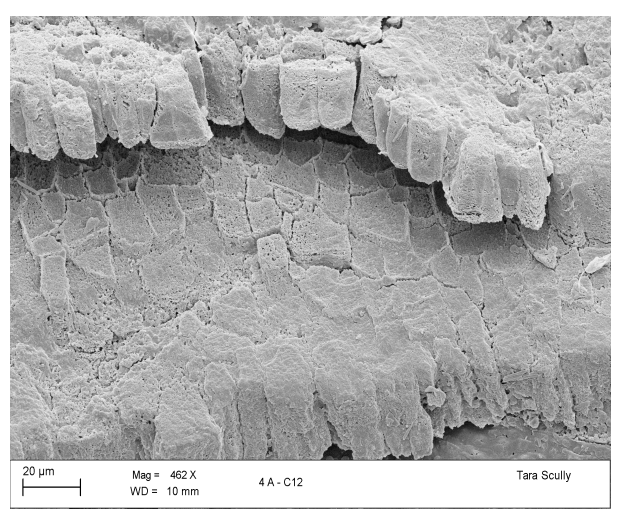

Figure 1c. The prismatic layer found mainly on the outer shell layer grows as long prisms which are separate but connected due to large amounts of organic matrix.

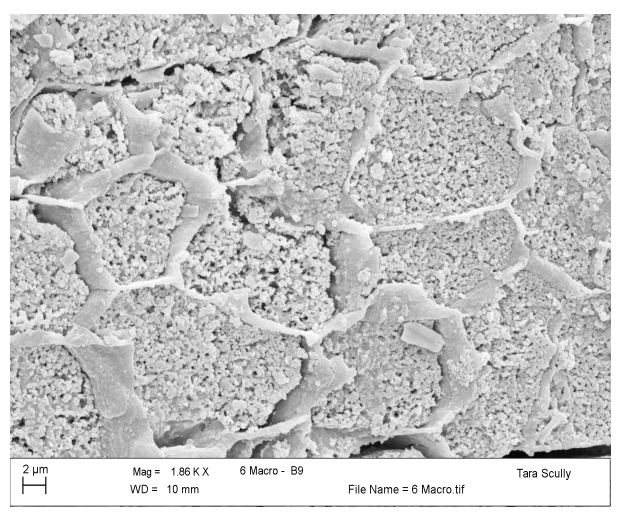

Figure 1d. Homogenous and granular are the same structures labeled based on size. Homogenous is a term designated for convenience for any fine-grained structure and granular refers to aggregates of these structures.

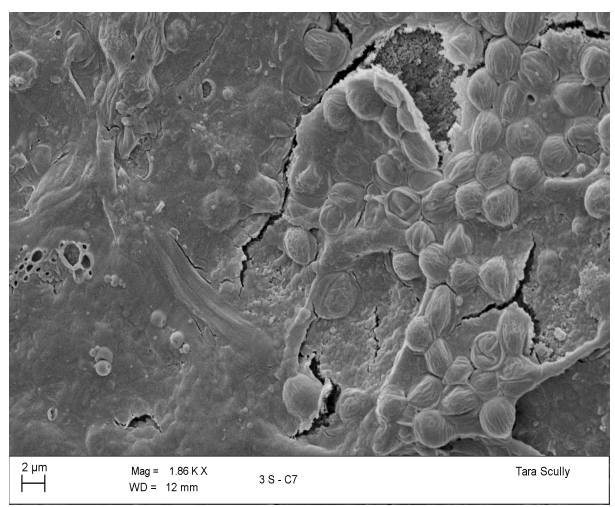

Figures 1e. Core shell grains 1, Sheath. Core shell grains 1 were only found in the sheath structures. Sheath structures were found in the experimental analysis of foliated structure growth [8] (journal). 
Statistical Analysis of GLCM Texture Features and Microstructures in SEM Images ... A. Khan et al.

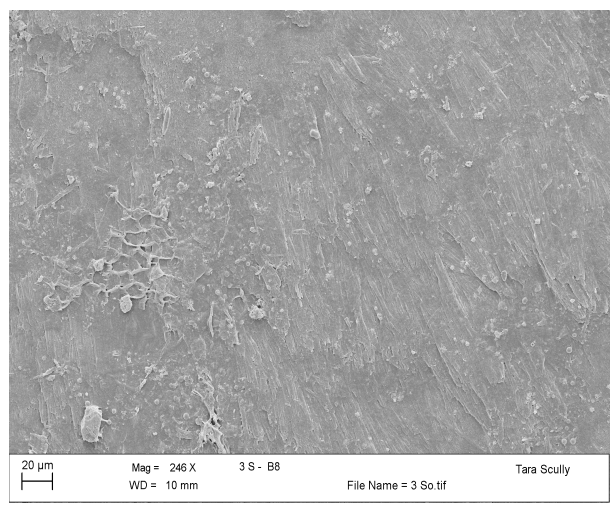

Figure 1f. Core shell grain 2 structures have been imaged as a stage in nacreous layer formation [10] (book).

\section{Methods}

\subsection{Oyster Shell Collection and treatment}

The oyster spats used were purchased from Horn Point Laboratory in April 2016. 250 oyster spats were chosen and divided into 5 subgroups of 50 oysters each as seen in table 1 . In order to determine effects of atrazine on shell growth at concentrations relevant to the current environmental scenarios, three atrazine concentrations were chosen for testing. An additional group with acetone was created since acetone was used as the solvent in atrazine treatment. The experimental groups were introduced to atrazine after a three month stabilization period. The oyster groups were placed in four individual 4-liter glass tanks with the assigned atrazine and acetone concentrations. The treatments were conducted twice a week for 30 days after which the oysters were given a 30 day recovery period. At the end of the treatment and recovery periods the groups were divided into two groups for SEM image analysis: Group A, shells that were not given a recovery period, and Group B, shells that were given a recovery period. However, an unpaired t-test between the two groups showed that there was no difference between the microstructures and computational features between the two groups. Therefore, the two groups were combined during analysis. 
Statistical Analysis of GLCM Texture Features and Microstructures in SEM Images ... A. Khan et al.

\begin{tabular}{cl}
\hline $\begin{array}{c}\text { Atrazine and } \\
\text { Acetone } \\
\text { concentration/ } \mu \mathrm{g} / \mathrm{L}\end{array}$ & \multicolumn{1}{c}{ Environmental Significance } \\
$30 \mu \mathrm{g} / \mathrm{L}$ atrazine & $\begin{array}{l}\text { Peak concentration of atrazine } \\
\text { detected in any surface water } \\
\text { sample in the Chesapeake Bay. }\end{array}$ \\
$10 \mu \mathrm{g} / \mathrm{L}$ atrazine & $\begin{array}{l}\text { Highest recorded concentration } \\
\text { of atrazine concentration in 2011 } \\
\text { from upper Choptank River. }\end{array}$ \\
$3 \mu \mathrm{g} / \mathrm{L}$ atrazine & $\begin{array}{l}\text { The EPA's Maximum Residue } \\
\text { Limit (MRL) for atrazine. } \\
\text { 100\% acetone solution was used } \\
30 \mu \mathrm{g} / \mathrm{L} \text { acetone }\end{array}$ \\
$0 \mu \mathrm{g} / \mathrm{L}$ & $\begin{array}{l}\text { Co dissolve atrazine. } \\
\text { Control group for comparison. }\end{array}$ \\
\hline
\end{tabular}

Table 1: Atrazine and Acetone concentrations assigned to each experimental oyster group [7] (journal), [13], [14] (online)

\subsection{SEM Observation of shells}

The collected number of shells from each experimental group was as follows: 7 from $30 \mu \mathrm{g} / \mathrm{L}$ Atrazine, 3 from $10 \mu \mathrm{g} / \mathrm{L}$ Atrazine, 3 from $3 \mu \mathrm{g} / \mathrm{L}$ Atrazine, 7 from $30 \mu \mathrm{g} / \mathrm{L}$ Acetone and 6 from $0 \mu \mathrm{g} / \mathrm{L}$ of Atrazine (control). For scanning electron microscopy (SEM), images were taken using the LEO 1430VP at the Department of Biology of The George Washington University. To prepare the specimens for SEM, the shells were washed in deionized water for 24 hours before air drying. The specimens were sputter-coated in a gold-palladium alloy for 270 seconds. Images were taken in 3 different regions of the shell (Figure 2). A total of 7 images were taken of each oyster at two different magnifications (x1860 and x246). All confidential information regarding treatments was anonymized prior to data analysis.

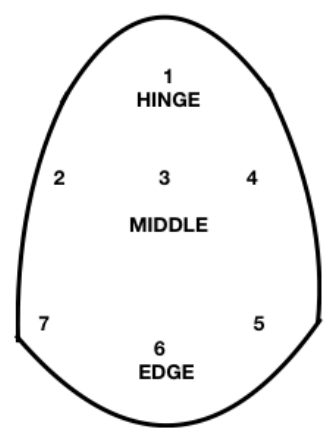

Figure 2: Regions of the shell imaged using the SEM

\subsection{User-Labeled Data Analysis}

The microstructures observed in SEM images were labelled with the standardized microstructures as seen in figure 1. The labeling was tabulated according to the microstructures seen in hinge, middle and edge of the shell. These microstructure tabulations were then averaged from each region of the shell across each experimental group. A unpaired t-test was used to assess the differences in micro structures between the experimental groups. The different groups were categorized as follows: (1) $0 \mu \mathrm{g} / \mathrm{L}$ of Atrazine vs. $3 \mu \mathrm{g} / \mathrm{L}$ of Atrazine, (2) $0 \mu \mathrm{g} / \mathrm{L}$ of Atrazine vs. $10 \mu \mathrm{g} / \mathrm{L}$ of Atrazine, (3) $0 \mu \mathrm{g} / \mathrm{L}$ of 
Atrazine vs. $30 \mu \mathrm{g} / \mathrm{L}$ of Atrazine, (4) $0 \mu \mathrm{g} / \mathrm{L}$ of Atrazine vs. $30 \mu \mathrm{g} / \mathrm{L}$ of Acetone, (5) $30 \mu \mathrm{g} / \mathrm{L}$ of Acetone vs. $3 \mu \mathrm{g} / \mathrm{L}$ of Atrazine, (6) $30 \mu \mathrm{g} / \mathrm{L}$ of Acetone vs. $10 \mu \mathrm{g} / \mathrm{L}$ of Atrazine, (7) $30 \mu \mathrm{g} / \mathrm{L}$ of Acetone vs. $30 \mu \mathrm{g} / \mathrm{L}$ of Atrazine. A value of $\mathrm{p}<0.01$ was considered to be statistical significance. Three additional t-test were conducted to see if there was a varying frequencies of microstructures in the three different regions (hinge, middle, edge) of the shell.

\subsection{Texture Analysis}

MATLAB $®$ (Mathworks, Natick, MA) was used to write all programs for the image analysis (a graphical user interface was created to help assist with analysis). Analysis was done in three steps (1) noise in the image was removed using median filtering, (2) Haralick's features were calculated from the Gray-level co-occurrence matrix (GLCM) of the image, (3), features were selected using a multiple comparison t-test. The GLCM is a statistical method that calculates how often pairs of pixel with specified values and spatial orientation occur in an image. It is often represented as a matrix where the number of rows and columns are equal to the number of quantized gray levels, in the image [3] (journal). For our images we apply a quantization level of 256 with a offset degree of 0.19 different features were computed from the GLCM: Auto Correlation, Cluster Prominence, Cluster Shade, Contrast, Correlation, Difference Entropy, Difference Variance, Dissimilarity Energy, Entropy, Homogeneity, Information Measure Of Correlation 1, Information Measure Of Correlation 2, Inverse Difference, Maximum Probability, Sum Average, Sum Entropy, Sum Of Squares Variance, and Sum Variance [12] (journal). To reduce the number of required features to the best features for differentiating the different concentrations of atrazine from the control, an unpaired t-test was used to examine the significance of the difference between the different groups. The different groups are described in the previous section.

\section{Results}

\subsection{User-Labeled Data}

Multivariate t-test conducted between $0 \mu \mathrm{g} / \mathrm{L}$ of Atrazine against experimental groups with a cumulation of all microstructures yielded insignificant results $(\mathrm{p}>0.01)$ across all groups. Similar results were acquired with $30 \mu \mathrm{g} / \mathrm{L}$ of Acetone treated groups against all experimental groups. The three additional t-test conducted were as follows:

1. T-test for the foliated and nacreous microstructures at the hinge: The foliated and nacreous microstructures during tabulation were the most frequently occurring microstructures at the hinge.

2. T-test for all structures excluding nacreous and foliated at the edge: The average foliated and nacreous microstructures at the edge were 0 or close to zero in most shells which would produce a skewed p-value when evaluating all microstructures.

3. T-test for prismatic and homogeneous microstructures at the edge: The prismatic and homogeneous microstructures were found in most abundance at the edge.

Results for the unpaired statistical tests are displayed in tables 2 and 3. A significance was seen in the frequency of prismatic and homologous structures at the edge for t-test conducted with $0 \mu \mathrm{g} / \mathrm{L}$ Atrazine against $10 \mu \mathrm{g} / \mathrm{L}$ Atrazine $(\mathrm{p}=0.01)$, and $30 \mu \mathrm{g} / \mathrm{L}$ Acetone against $10 \mu \mathrm{g} / \mathrm{L}$ Atrazine $(\mathrm{p}=0.00087)$. Additionally, a significance was seen when a t-test was conducted excluding nacreous and foliated structures at the edge. This was observed with $0 \mu \mathrm{g} / \mathrm{L}$ Atrazine against $10 \mu \mathrm{g} / \mathrm{L}$ Atrazine $(\mathrm{p}=0.0094)$, and $30 \mu \mathrm{g} / \mathrm{L}$ Acetone against $10 \mu \mathrm{g} / \mathrm{L}$ Atrazine $(\mathrm{p}=0.00099)$. 
Statistical Analysis of GLCM Texture Features and Microstructures in SEM Images ... A. Khan et al.

\begin{tabular}{llll}
\hline $\begin{array}{l}\text { Microstructure } \\
\text { grouping }\end{array}$ & $\begin{array}{l}3 \mu \mathrm{g} / \mathrm{L} \\
\text { Atrazine }\end{array}$ & $\begin{array}{l}10 \mu \mathrm{g} / \mathrm{L} \\
\text { Atrazine }\end{array}$ & $\begin{array}{l}30 \mu \mathrm{g} / \mathrm{L} \\
\text { Atrazine }\end{array}$ \\
$\begin{array}{l}\text { Hinge: } \\
\text { Foliated and }\end{array}$ & 0.763 & 0.763 & 0.686 \\
$\begin{array}{l}\text { Nacreous } \\
\begin{array}{l}\text { Edge: No } \\
\text { nacreous and } \\
\text { foliated }\end{array}\end{array}$ & 0.296 & 0.009 & 0.670 \\
$\begin{array}{l}\text { Edge: } \\
\text { Prismatic and } \\
\text { Homogenous }\end{array}$ & 0.350 & 0.010 & 0.710 \\
\hline
\end{tabular}

Table 2: Unpaired statistical test for additional t-tests conducted for $0 \mu \mathrm{g} / \mathrm{L}$ Atrazine vs. other experimental groups

\begin{tabular}{lllll}
\hline $\begin{array}{l}\text { Microstructure } \\
\text { grouping }\end{array}$ & $\begin{array}{l}0 \mu \mathrm{g} / \mathrm{L} \\
\text { Atrazine }\end{array}$ & $\begin{array}{l}3 \mu \mathrm{g} / \mathrm{L} \\
\text { Atrazine }\end{array}$ & $\begin{array}{l}10 \mu \mathrm{g} / \mathrm{L} \\
\text { Atrazine }\end{array}$ & $\begin{array}{l}30 \mu \mathrm{g} / \mathrm{L} \\
\text { Atrazine }\end{array}$ \\
$\begin{array}{l}\text { Hinge: } \\
\text { Foliated and }\end{array}$ & 0.292 & 0.289 & 0.289 & 0.124 \\
$\begin{array}{l}\text { Nacreous } \\
\begin{array}{l}\text { Edge: No } \\
\text { nacreous and } \\
\text { foliated }\end{array}\end{array}$ & 0.451 & 0.010 & 0.001 & 0.244 \\
$\begin{array}{l}\text { Edge: } \\
\text { Prismatic and }\end{array}$ & 0.483 & 0.155 & 0.001 & 0.760 \\
Homologous & & & & \\
\hline
\end{tabular}

Table 3 Unpaired statistical test for additional t-tests conducted for $30 \mu \mathrm{g} / \mathrm{L} \mathrm{A}$ trazine vs. other experimental groups

\subsection{Feature Extraction}

Results from unpaired statistical tests are displayed in Tables 4 and 5 comparing the significant Haralick's features (HF) capable of distinguishing between all 5 groups. Overall, the metrics for choosing statistically significant HFs were chosen with corresponding p-values $<.01$. Starting with the hinge region, Homogeneity $(\mathrm{p}=.0063)$ and Inverse Difference $(\mathrm{p}=.0068)$ were significantly capable of distinguishing between the Control and acetone treated shells. Likewise, Entropy, Sum Entropy, Sum of Squares Variance, and Sum Variances were significantly different between acetone and $30 \mu \mathrm{g} / \mathrm{L}$ atrazine in the same respective region. The middle region showed no significance, however, the edge region showed the most promising results. The edges of the control and $30 \mu \mathrm{g} / \mathrm{L}$ atrazine group had a significant difference in features between difference entropy, dissimilarity, homogeneity, inverse difference. The edges for the $30 \mu \mathrm{g} / \mathrm{L}$ atrazine and acetone groups has significant differences in dissimilarity, energy, entropy, homogeneity, difference entropy, contrast, inverse difference. Conversely, we observed no significant differences between the $3 \mu \mathrm{g} / \mathrm{L}$ atrazine and $10 \mu \mathrm{g} / \mathrm{L}$ atrazine groups. 
Statistical Analysis of GLCM Texture Features and Microstructures in SEM Images ... A. Khan et al.

\begin{tabular}{llll}
\hline Features & $\begin{array}{l}3 \mu \mathrm{g} / \mathrm{L} \\
\text { Atrazine }\end{array}$ & $\begin{array}{l}10 \mu \mathrm{g} / \mathrm{L} \\
\text { Atrazine }\end{array}$ & $\begin{array}{l}30 \mu \mathrm{g} / \mathrm{L} \\
\text { Atrazine }\end{array}$ \\
Contrast & 0.103 & 0.050 & 0.016 \\
Difference & 0.079 & 0.045 & 0.008 \\
Entropy & & & \\
Dissimilarity & 0.064 & 0.032 & 0.007 \\
Energy & 0.299 & 0.185 & 0.015 \\
Entropy & 0.328 & 0.231 & 0.013 \\
Homogeneity & 0.035 & 0.035 & 0.004 \\
Inverse & 0.051 & 0.033 & 0.004 \\
Difference & & & \\
\hline
\end{tabular}

Table 4 Unpaired statistical test of Harlick's features (HF) for $0 \mu \mathrm{g} / \mathrm{L}$ Atrazine vs. other experimental group

\begin{tabular}{lllll}
\hline Features & $\begin{array}{l}0 \mu \mathrm{g} / \mathrm{L} \\
\text { Atrazine }\end{array}$ & $\begin{array}{l}3 \mu \mathrm{g} / \mathrm{L} \\
\text { Atrazine }\end{array}$ & $\begin{array}{l}10 \mu \mathrm{g} / \mathrm{L} \\
\text { Atrazine }\end{array}$ & $\begin{array}{l}30 \mu \mathrm{g} / \mathrm{L} \\
\text { Atrazine }\end{array}$ \\
$\begin{array}{l}\text { Contrast } \\
\text { Difference }\end{array}$ & 0.006 & 0.493 & 0.727 & 0.120 \\
Entropy & 0.005 & 0.494 & 0.848 & 0.144 \\
$\begin{array}{l}\text { Dissimilarity } \\
\text { Energy }\end{array}$ & 0.003 & 0.605 & 0.635 & 0.141 \\
Entropy & 0.010 & 0.196 & 0.203 & 0.364 \\
& 0.009 & 0.224 & 0.252 & 0.364 \\
$\begin{array}{l}\text { Homogeneity } \\
\text { Inverse }\end{array}$ & 0.003 & 0.607 & 0.952 & 0.239 \\
Difference & 0.003 & 0.618 & 0.876 & 0.225 \\
\hline
\end{tabular}

Table 5 Unpaired statistical test of Harlick's features (HF) for $30 \mu \mathrm{g} / \mathrm{L}$ Acetone vs. other experimental group

\section{Discussion}

This paper proposed a novel framework to quantify and assess the statistical significance of microstructures and classify textural features in SEM images of Crassostrea Virginica treated with Atrazine. Our pilot experimental results provide computational strategies to identify oysters that have been exposed to high concentrations of Atrazine. The statistical analysis of the user tabulated microstructures showed a significant difference between the edge regions of the $10 \mu \mathrm{g} / \mathrm{L}$ Atrazine and $0 \mu \mathrm{g} / \mathrm{L}$ Atrazine treated shells. This is important as the edge region of the shell represents the new growth layer. Since the types of microstructures that appeared in this region differed from those that were in the control group, it can be said that atrazine had some effect on the maintenance and growth of the shell even though the exact mechanism by which microstructures appear in different regions of the shell is still largely unknown.

The results for the feature extraction showed a significant difference for the edge regions of shells treated with $30 \mu \mathrm{g} / \mathrm{L}$ atrazine vs. $0 \mu \mathrm{g} / \mathrm{L}$ atrazine. From Table 4, the high entropy values calculated for the edge image in the oyster implies that the elevated level of disorder occurred due to the $30 \mu \mathrm{g} / \mathrm{L}$ of atrazine. The difference in the entropy values near the edge can represent the variation of microstructures seen in the atrazine treated shells, indicating abnormal shell growth. The Sum 
Entropy, Sum of Squares Variance, and Sum Variances are also features that can be considered as significant biomarkers to differentiate between the $30 \mu \mathrm{g} / \mathrm{L}$ of atrazine from the normal shells.

Our results indicate that textural analysis has the potential to develop into valuable biological tools that improve the diagnosis of biological conditions. While our results are promising, there is still further work that can be done in detecting the abnormality of the shell surface when exposed to atrazine and other pollutants. Here, a preliminary investigation has been done using statistical analysis to identify the most useful texture features and microstructures that can be fed to any classification technique later. Our future work also includes considering more flexible area divisions, evaluating other physical measures of the shell with different observations of microstructures, extending treatment periods and applying machine learning classifiers to develop a predictive system and experimenting with larger datasets. In addition, the shell growth data will be compared against oyster transcriptome analysis to show the overall effect of Atrazine on the eastern oyster.

\section{Acknowledgements}

We would like to first acknowledge Dr. Scully for her continued support and evaluation through the timeline of this project. We would also like to thank the Biology Department at the George Washington University for providing us with the necessary tools and members of Dr. Gustavo Hormiga's lab for their valuable assistance in generating the data.

\section{References}

[1] Frank Ackerman. The Economics of Atrazine. International Journal of Occupational and Environmental Health, 13:441-449, 2007.

[2] Karine Bouilly, Alexandra Leita O, Helen McCombie, and Sylvie Lapegue. Impact of Atrazine on Aneuploidy in Pacific Oysters, Crassostrea Gigas. Environmental Toxicology and Chemistry, 22(1):219-223, 2003.

[3] David A. Clausi. An analysis of co-occurrence texture statistics as a function of grey level quantization. Canadian Journal of Remote Sensing, 28: 45-62, 2002.

[4] W. Gómez, W.C.A. Pereira, and A.F.C. Infantosi. Analysis of Co-Occurrence Texture Statistics as a Function of Gray-Level Quantization for Classifying Breast Ultrasound. IEEE Transactions on Medical Imaging, 31(10): 1889-1899, 2012.

[5] Robert M. Haralick, K. Shanmugam, and Its'Hak Dinstein. Textural Features for Image Classification. IEEE Transactions on Systems, Man, and Cybernetics, 3(6): 610-621, 1973.

[6] Tyrone Hayes, Kelly Haston, Mable Tsui, Anhthu Hoang, Cathryn Haeffele, and Aaron Vonk. Atrazine-Induced Hermaphroditism at $0.1 \mathrm{ppb}$ in American Leopard Frogs (Rana pipiens): Laboratory and Field Evidence. Environmental Health Perspectives, 111: 568-575, 2003.

[7] W. D. Hively, C. J. Hapeman, L. L. McConnell, T. R. Fisher, C. P. Rice, G. W. McCarty, Sadeghi AM, Whitall DR, Downey PM, Niño de Guzmán GT, Bialek-Kalinski K, Lang MW, Gustafson AB, Sutton AJ, Sefton KA, and Harman Fetcho JA. Relating nutrient and herbicide fate with landscape features and characteristics of 15 subwatersheds in the Choptank River watershed. Science of the total environment, 409(19): 3866-3878, 2011.

[8] M.B. Johnstone, N.V. Gohad, E.P. Falwell, D.C. Hansen, K.M. Hansen, and A.S. Mount. Cellular orchestrated biomineralization of crystalline composites on implant surfaces by the eastern oyster, crassostrea virginica (gmelin, 1791). Journal of Experimental Marine Biology and Ecology, 463 8-16. [9] Karl M. Wilbur and A. S. M. Saleuddin. The mollusca, Academic Press, Volume 4, 1983. 
Statistical Analysis of GLCM Texture Features and Microstructures in SEM Images ... A. Khan et al.

[10] Karl M. Wilbur and C. M. Yonge. Physiology of mollusca, Academic Press, Volume 2, 1964.

[11] Meiqing Zhu, Lijun Wang, JieZhou, Wei Lu, Yue Xin, Shisuo Fan, Zhen Wang, and Yi Wang. Biointeractions of Herbicide Atrazine with Human Serum Albumin: UV-Vis, Fluorescence and Circular Dichroism Approaches. International Journal of Environmental Research and Public Health, 15 (116), 2018.

[12] Nitish Zulpe and Pawar Vrushsen. GLCM Textural Features for Brain Tumor Classification. IJCSI International Journal of Computer Science Issues, 9(3): 354-359, 2012.

[13] US Environmental Protection Agency, US Geological Survey, US Fish and Wildlife Service, 2012 Toxic Contaminants in the Chesapeake Bay and its Watershed: Extent and Severity of Occurrence and Potential Biological Effects, USEPA Chesapeake Bay Program Office, Annapolis, MD, December, 2012, 175 pages (46-58).

[14] U.S. Environmental Protection Agency, National pesticide survey, 1990. 